\title{
Phase Stability and Miscibility in Ethanol/AOT/n-heptane Systems: Evidence of Multilayered Cylindrical and Spherical Microemulsion Morphologies
}

\section{SUPPLEMENTARY INFORMATION}

Robyn E. Ridley, Erick Alvarado, Anthony A. Mrse, Victor R. Vasquez, Olivia A. Graeve*

* Corresponding Author

Olivia A. Graeve - Department of Mechanical and Aerospace Engineering, University of California San Diego, La Jolla, CA 92093-0411, United States of America; Email:

ograeve@ucsd.edu; URL: http://graeve.ucsd.edu/; orcid.org/0000-0003-3599-0502

\section{Authors}

Robyn E. Ridley - Department of Mechanical and Aerospace Engineering, University of California San Diego, La Jolla, CA 92093-0411, United States of America; orcid.org/000-0002-7281-982X

Erick Alvarado - Department of Mechanical and Aerospace Engineering, University of California San Diego, La Jolla, CA 92093-0411, United States of America

Anthony A. Mrse - Department of Chemistry and Biochemistry, University of California San Diego, La Jolla, CA 92093-0307, United States of America; orcid.org/0000-00020563-9917

Victor R. Vasquez - Chemical and Materials Engineering, University of Nevada, Reno, NV 89557, United States of America; orcid.org/0000-0002-6604-8096 
Table S1. Amounts of ethanol and AOT added to $50 \mathrm{~mL}$ of $n$-heptane for all ethanol/AOT $/ n$ heptane compositions used for DLS experiments. The ethanol-to-surfactant mole ratio $\left(w_{\mathrm{s}}\right)$ is also given for each composition.

\begin{tabular}{|c|c|c|c|}
\hline $\begin{array}{c}\text { Composition } \\
\text { (wt.\%) } \\
\text { (etOH/AOT/n- } \\
\text { heptane) }\end{array}$ & $w_{\mathrm{s}}$ & $\begin{array}{c}\text { Ethanol } \\
(\mathrm{mL})\end{array}$ & $\begin{array}{c}\text { AOT } \\
(\mathrm{g})\end{array}$ \\
\hline $0 / 10 / 90$ & 0 & 0 & 3.809 \\
\hline $0 / 40 / 60$ & 0 & 0 & 22.20 \\
\hline $3 / 3 / 94$ & 10 & 1.1 & 0.899 \\
\hline $3 / 5 / 92$ & 5 & 1.2 & 1.848 \\
\hline $3 / 10 / 87$ & 3 & 1.5 & 3.809 \\
\hline $3 / 15 / 82$ & 2 & 1.3 & 6.216 \\
\hline $3 / 20 / 77$ & 1 & 1.4 & 8.823 \\
\hline $3 / 25 / 72$ & 0.9 & 1.5 & 11.79 \\
\hline $3 / 30 / 67$ & 0.8 & 1.6 & 15.19 \\
\hline $3 / 35 / 62$ & 0.7 & 1.7 & 19.15 \\
\hline $4 / 38 / 58$ & 1 & 2.9 & 22.20 \\
\hline $10 / 5 / 85$ & 19 & 5.1 & 2.011 \\
\hline $10 / 9 / 81$ & 10 & 5.0 & 3.809 \\
\hline $10 / 15 / 75$ & 6 & 5.8 & 6.838 \\
\hline $10 / 20 / 70$ & 5 & 6.2 & 9.769 \\
\hline $10 / 25 / 70$ & 4 & 6.7 & 13.15 \\
\hline $10 / 30 / 60$ & 3 & 7.2 & 17.09 \\
\hline $10 / 35 / 55$ & 2 & 7.9 & 21.76 \\
\hline $13 / 9 / 78$ & 15 & 7.5 & 3.809 \\
\hline $15 / 5 / 80$ & 29 & 8.2 & 2.137 \\
\hline $15 / 15 / 70$ & 10 & 9.3 & 7.326 \\
\hline $15 / 20 / 65$ & 7 & 10.0 & 10.52 \\
\hline $15 / 25 / 60$ & 6 & 10.9 & 14.25 \\
\hline $17 / 8 / 75$ & 20 & 10.0 & 3.809 \\
\hline $17 / 33 / 50$ & 5 & 14.6 & 22.20 \\
\hline $20 / 40 / 40$ & 5 & 21.7 & 34.20 \\
\hline $23 / 5 / 72$ & 43 & 13.5 & 2.358 \\
\hline
\end{tabular}

\begin{tabular}{|c|c|c|c|}
\hline $\begin{array}{c}\text { Composition } \\
\text { (wt.\%) } \\
\text { (etOH/AOT/n- } \\
\text { heptane) }\end{array}$ & $w_{\mathrm{s}}$ & $\begin{array}{c}\text { Ethanol } \\
(\mathrm{mL})\end{array}$ & $\begin{array}{c}\text { AOT } \\
(\mathrm{g})\end{array}$ \\
\hline $23 / 10 / 67$ & 22 & 14.5 & 5.065 \\
\hline $23 / 15 / 62$ & 14 & 15.7 & 8.206 \\
\hline $23 / 20 / 57$ & 11 & 17.0 & 11.89 \\
\hline $23 / 25 / 52$ & 9 & 18.6 & 16.28 \\
\hline $23 / 30 / 47$ & 7 & 20.6 & 21.59 \\
\hline $27 / 29 / 44$ & 9 & 14.6 & 22.20 \\
\hline $30 / 10 / 60$ & 29 & 21.7 & 5.698 \\
\hline $30 / 15 / 55$ & 19 & 23.7 & 9.325 \\
\hline $30 / 20 / 50$ & 14 & 26.1 & 13.68 \\
\hline $32 / 7 / 61$ & 45 & 22.5 & 3.809 \\
\hline $38 / 6 / 56$ & 60 & 30.0 & 3.809 \\
\hline $38 / 10 / 52$ & 36 & 31.1 & 6.512 \\
\hline $38 / 15 / 47$ & 24 & 34.3 & 10.79 \\
\hline $38 / 20 / 42$ & 18 & 38.4 & 16.09 \\
\hline $38 / 25 / 37$ & 14 & 43.5 & 22.79 \\
\hline $38 / 30 / 32$ & 12 & 50.2 & 31.56 \\
\hline $45 / 6 / 49$ & 80 & 40.0 & 3.809 \\
\hline $45 / 10 / 45$ & 43 & 43.5 & 7.598 \\
\hline $45 / 15 / 40$ & 29 & 48.9 & 12.82 \\
\hline $45 / 20 / 35$ & 22 & 55.9 & 19.54 \\
\hline $45 / 25 / 30$ & 17 & 65.2 & 28.49 \\
\hline $45 / 30 / 25$ & 14 & 78.3 & 41.03 \\
\hline $50 / 10 / 40$ & 48 & 54.4 & 8.548 \\
\hline $50 / 15 / 35$ & 32 & 62.1 & 14.65 \\
\hline $50 / 20 / 30$ & 24 & 72.5 & 22.79 \\
\hline $50 / 25 / 25$ & 19 & 86.9 & 34.19 \\
\hline $51 / 5 / 44$ & 100 & 50 & 3.809 \\
\hline & & & \\
\hline
\end{tabular}


Table S2. Compositions and quantities of molecules used in the MD simulations.

\begin{tabular}{|c|c|c|c|c|}
\hline $\begin{array}{c}\text { Composition } \\
\text { diagram point }\end{array}$ & $\begin{array}{c}\text { Composition (wt.\%) } \\
\text { (ethanol/AOT/n- } \\
\text { heptane) }\end{array}$ & $\begin{array}{c}\text { Ethanol } \\
\text { molecules }\end{array}$ & $\begin{array}{c}\text { AOT } \\
\text { molecules }\end{array}$ & $\begin{array}{c}n \text {-Heptane } \\
\text { molecules }\end{array}$ \\
\hline $\mathrm{A}$ & $3 / 10 / 87$ & 84 & 24 & 1092 \\
\hline $\mathrm{B}$ & $4 / 38 / 58$ & 132 & 132 & 936 \\
\hline $\mathrm{C}$ & $4 / 78 / 18$ & 200 & 400 & 400 \\
\hline $\mathrm{D}$ & $9 / 9 / 82$ & 260 & 24 & 972 \\
\hline $\mathrm{E}$ & $10 / 20 / 70$ & 261 & 59 & 867 \\
\hline $\mathrm{F}$ & $20 / 25 / 55$ & 400 & 60 & 540 \\
\hline $\mathrm{G}$ & $20 / 40 / 40$ & 520 & 108 & 480 \\
\hline $\mathrm{H}$ & $20 / 50 / 30$ & 612 & 156 & 432 \\
\hline $\mathrm{I}$ & $20 / 60 / 20$ & 672 & 216 & 312 \\
\hline $\mathrm{J}$ & $23 / 5 / 72$ & 475 & 12 & 701 \\
\hline $\mathrm{K}$ & $23 / 20 / 57$ & 558 & 83 & 546 \\
\hline $\mathrm{L}$ & $23 / 30 / 47$ & 570 & 48 & 570 \\
\hline $\mathrm{M}$ & $27 / 29 / 44$ & 648 & 72 & 480 \\
\hline $\mathrm{N}$ & $32 / 7 / 61$ & 624 & 12 & 552 \\
\hline $\mathrm{O}$ & $38 / 6 / 56$ & 701 & 12 & 475 \\
\hline $\mathrm{P}$ & $38 / 15 / 47$ & 737 & 24 & 428 \\
\hline $\mathrm{Q}$ & $38 / 30 / 32$ & 808 & 59 & 321 \\
\hline $\mathrm{R}$ & $45 / 6 / 49$ & 792 & 12 & 396 \\
\hline $\mathrm{S}$ & $45 / 20 / 35$ & 843 & 36 & 309 \\
\hline $\mathrm{T}$ & $51 / 5 / 44$ & 843 & 12 & 333 \\
\hline $\mathrm{U}$ & $50 / 15 / 35$ & 879 & 24 & 285 \\
\hline $\mathrm{V}$ & $50 / 25 / 25$ & 927 & 48 & 214 \\
\hline
\end{tabular}



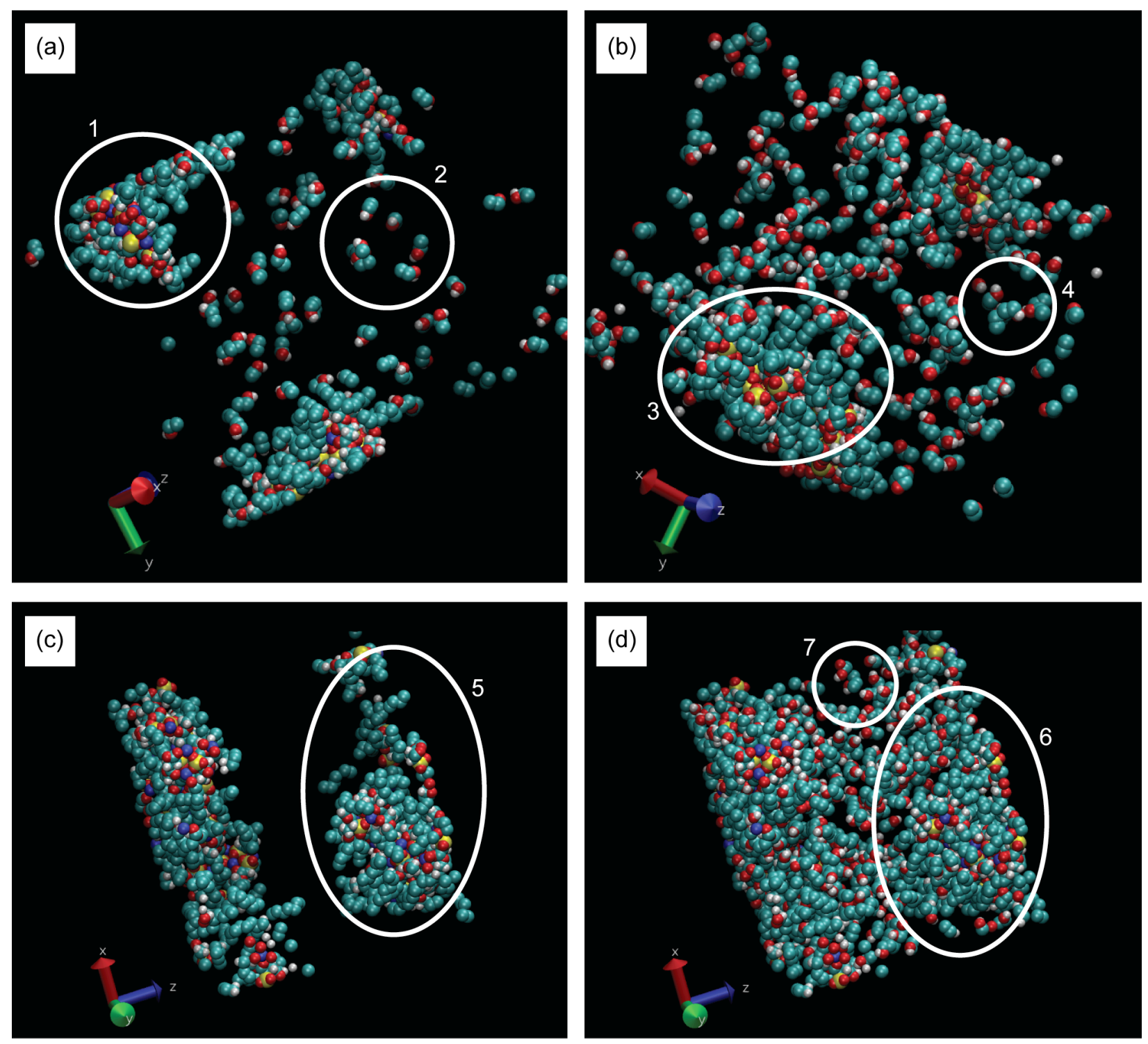

Figure S1. Snapshots of MD simulations of low-ethanol ( $\leq 20$ wt. $\%)$ and low-AOT ( $\leq 35$ wt. $\%)$ systems with compositions of (a) 3/9/88 wt.\% (composition diagram point A), (b) 10/9/81 wt.\% (composition diagram point D), and 20/25/55 wt.\% (composition diagram point $F$ ) with (c) ethanol hidden and (d) ethanol shown. All images show distinct AOT aggregates with some ethanol bonding at the AOT aggregate surfaces (circles 1, 3, and 6), while the majority of ethanol remains as free-floating clusters in heptane (circles 2, 4, and 7). Circle 5 contains the same AOT aggregate as circle 6, but with ethanol hidden. Colors represent the following atoms: carbon in light blue, hydrogen in white, sodium in dark blue, oxygen in red, and sulfur in yellow. 

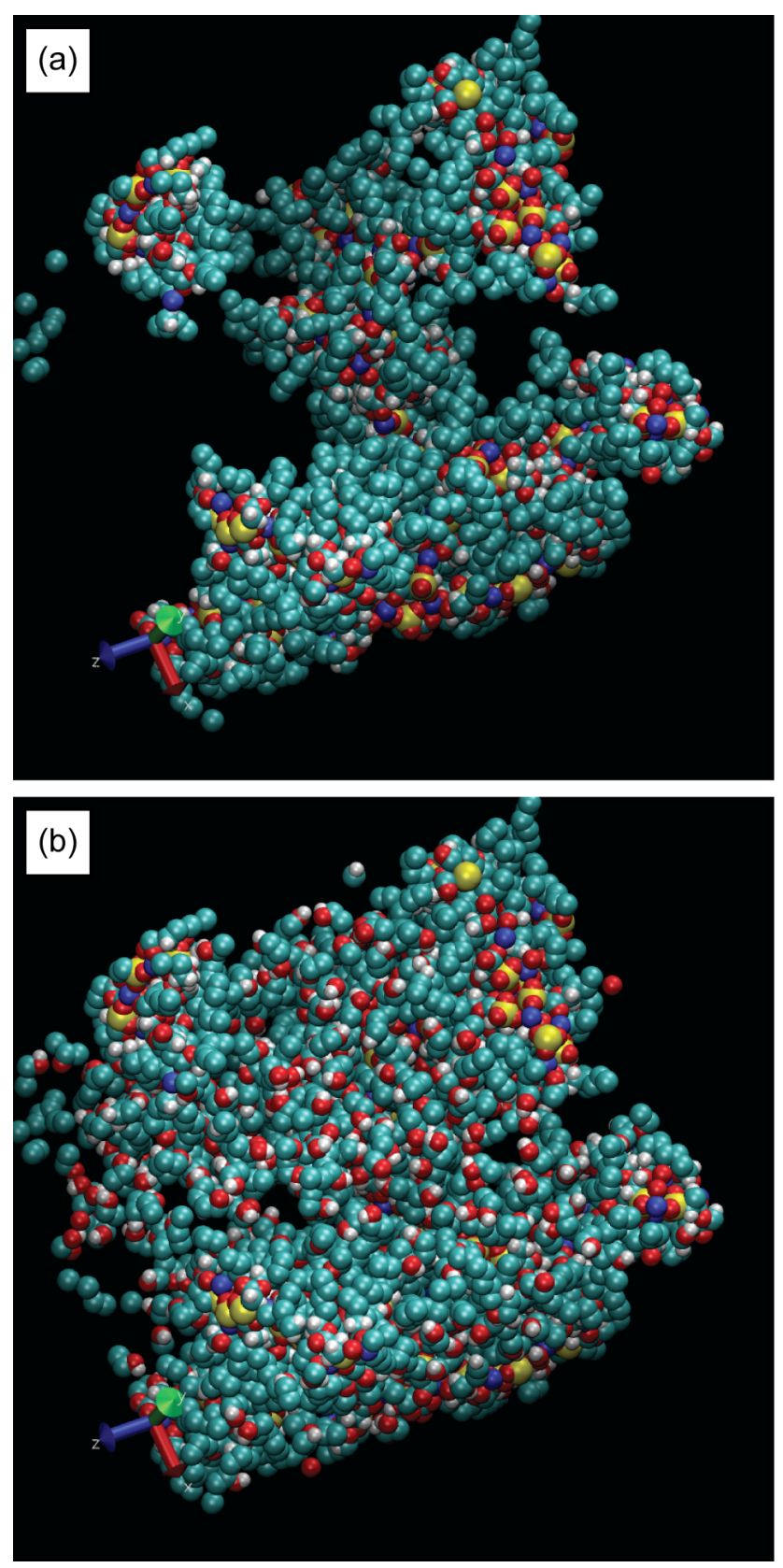

Figure S2. Snapshots of MD simulations of a low-ethanol $(\leq 20 \mathrm{wt} . \%)$ and high-AOT $(\geq 35$ wt.\%) system with a composition of 20/40/40 wt.\% (composition diagram point G) with ethanol (a) hidden and (b) shown. The limited solubility of AOT at low ethanol concentrations is indicated by increased AOT aggregate sizes and the $\mathrm{Na}^{+}$counterions (dark blue) remaining bonded to the surfactant headgroups (yellow sulfur atoms and red oxygen atoms). 


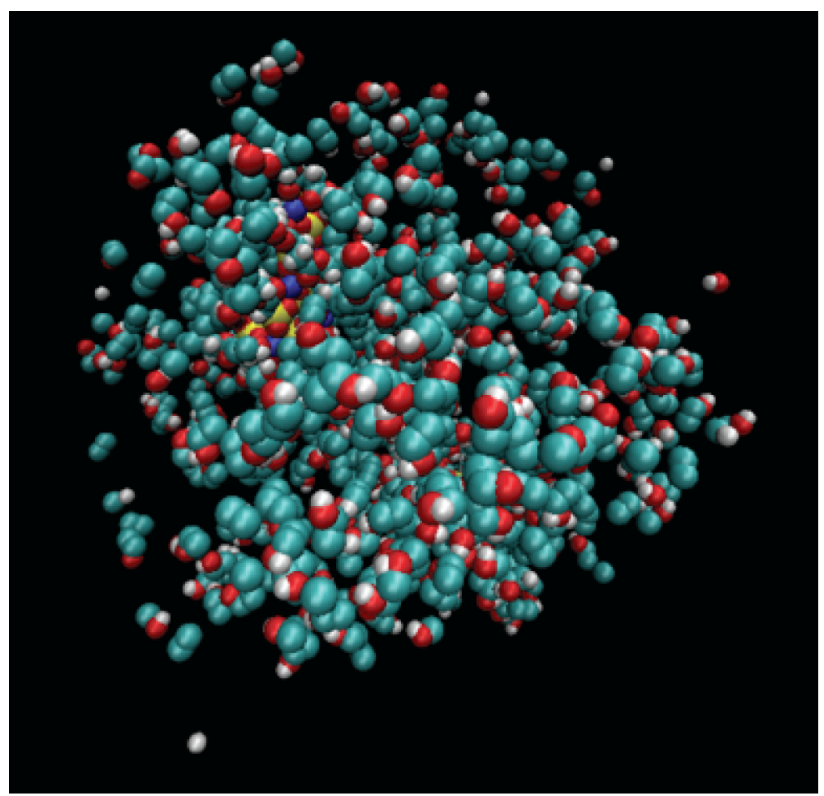

Figure S3. MD simulation of a 23/5/72 wt.\% ethanol/AOT/ $n$-heptane system (composition diagram point $\mathrm{J}$ ) showing an increased concentration of ethanol clusters (hydrogen: white, oxygen: red, carbon: light blue). Interactions between ethanol and AOT increase in this regime, but ethanol continues to behave as a co-surfactant at the surface of AOT aggregates, and AOT solubility continues to be limited with $\mathrm{Na}^{+}$counterions (dark blue) remaining unsolvated. 

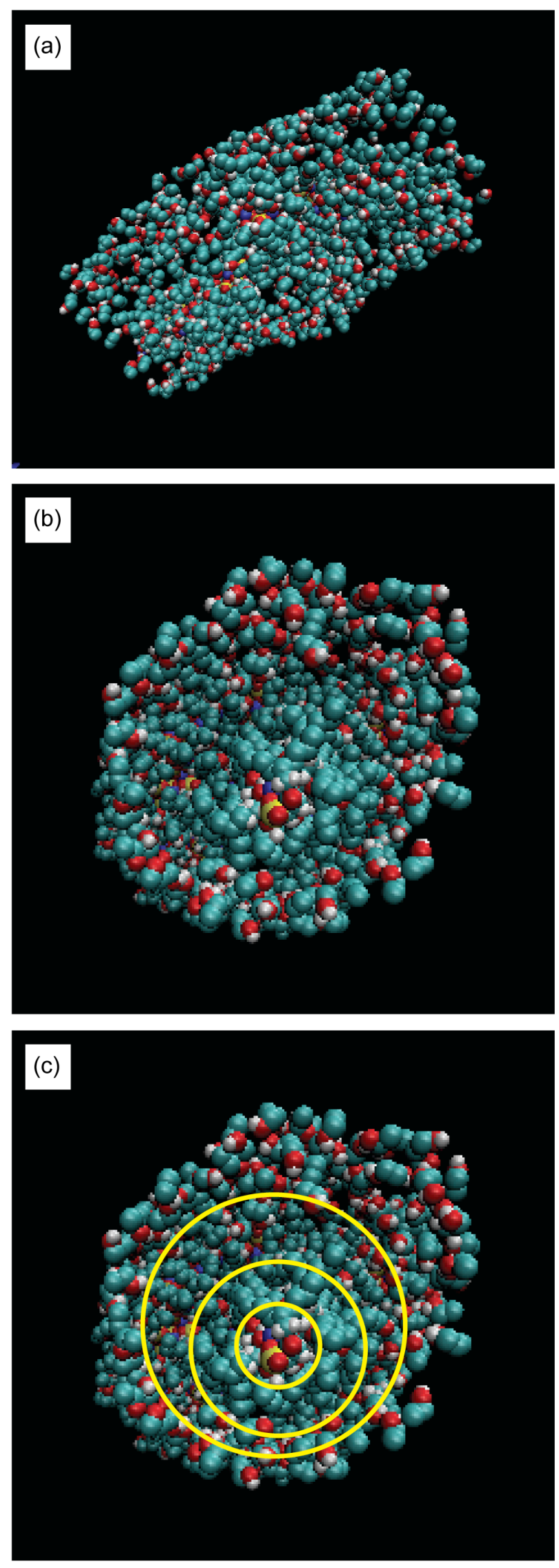

Figure S4. MD simulation snapshot of a 23/30/47 wt.\% ethanol/AOT/ $n$-heptane system (composition diagram point $\mathrm{L}$ ) showing a multilayer cylindrical structure, where (a) represents the side view and (b) represents the front view. Diagram (c) represents the image in (b) with visual aids. Four layers are formed in the following order from core to outer layer: (1) AOT aggregate, (2) surface-bonded ethanol, (3) $n$-heptane, and (4) ethanol. Increased hydrogen bonding among ethanol molecules is observed. Colors represent the following atoms: carbon in light blue, hydrogen in white, sodium in dark blue, oxygen in red, and sulfur in yellow. 

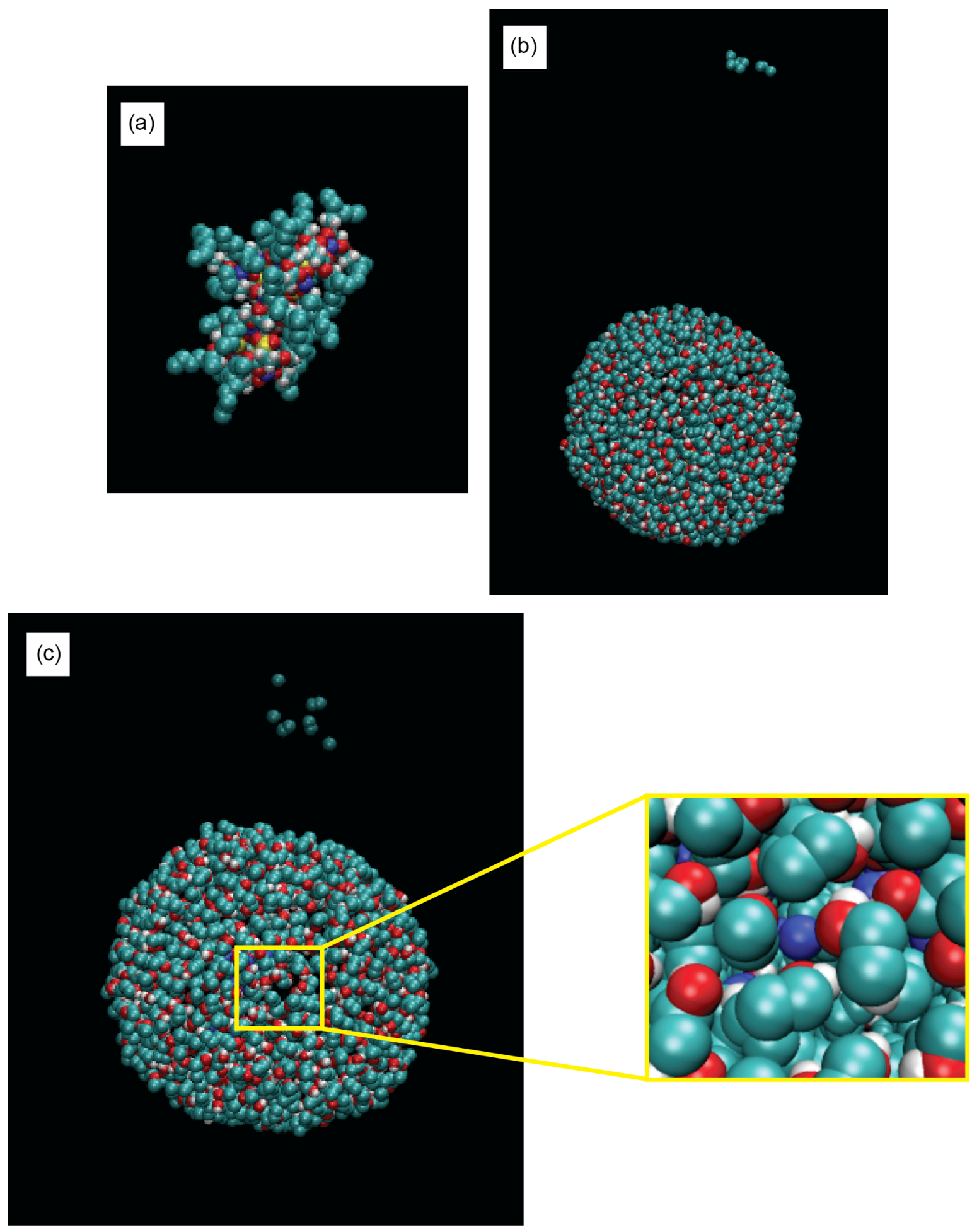

Figure S5. MD simulation snapshots for $45 / 6 / 49$ wt. $\%$ ethanol/AOT/ $n$-heptane with (a) ethanol hidden and AOT shown, (b) ethanol and AOT shown, and (c) only ethanol shown. A close-up of the spherical ethanol layer shows $\mathrm{Na}^{+}$counterions (dark blue) have been removed from the AOT headgroups to be solvated within the ethanol. Colors represent the following atoms: carbon in light blue, hydrogen in white, sodium in dark blue, oxygen in red, and sulfur in yellow. 